\title{
Use of at-sea distribution data to derive potential foraging ranges of macaroni penguins during the breeding season
}

\author{
P. N. Trathan*, E. J. Murphy, J. P. Croxall, I. Everson \\ British Antarctic Survey, Natural Environment Research Council, High Cross, Madingley Road, Cambridge CB3 0ET, \\ United Kingdom
}

\begin{abstract}
Macaroni penguins are the main avian consumer of Antarctic krill in the vicinity of South Georgia. The largest breeding colonies occur on small offshore islands to the northwest of the main island. To delimit the foraging range of penguins from these colonies during the chick-rearing period, we used a series of ship-based survey transects to estimate their distribution and abundance. The survey transects were positioned so as to radiate from a point close to those islands with the largest colonies. Spatial and temporal variations within the data are examined. Penguins were mostly over the continental shelf in water less than $350 \mathrm{~m}$ depth and with more than $70 \%$ of birds at distances less than $40 \mathrm{~km}$ from the main breeding site. To model the observed distribution of penguins, a theoretical at-sea distribution is developed together with a 'potential foraging footprint'. The results are compared with those from previous models based solely on the use of foraging trip duration and at-sea activity budgets. The foraging 'footprint' is probably the best basis currently available for assessing the nature of interactions between macaroni penguins and the commercial fisheries for krill.
\end{abstract}

KEY WORDS: Macaroni penguin $\cdot$ Foraging $\cdot$ At-sea $\cdot$ Colony counts $\cdot$ Eudyptes chrysolophus

\section{INTRODUCTION}

In order to elucidate predator-prey interactions within a marine ecosystem, information about the spatial distribution and abundance of predators and their prey is required. Knowledge of spatial structure is important because such patterns can fundamentally affect the operation and dynamics of species interactions (Everson 1984, Murphy 1995). In marine ecosystems the distribution of many species is constrained; for example many top predators are limited by their requirement for land access during certain times of the year. Such requirements can set important restrictions on the spatial scale of predator-prey interactions (Croxall et al. 1984). Thus, establishing where predators forage and how this relates to the location of their breeding site can be fundamental to understanding ecosystem interactions (Everson 1984).

·E-mail: p.trathan@bas.ac.uk
Three main methods are commonly used to estimate the at-sea distribution of marine predators. These are quantitative ship-based surveys of predator distribution and abundance at sea, radio or satellite tracking of foraging individuals, and timed duration of foraging trips coupled with information on species-specific activity budgets. Each of these methods has distinct advantages and disadvantages; for many species a combination of approaches may be appropriate.

The first method uses direct observation as part of a quantitative survey of avian predators and is based on well-established procedures (e.g. BIOMASS 1982, Buckland et al. 1993). Though the method is sometimes limited by a lack of information on predator activity (i.e. whether travelling or feeding) and by an inability to distinguish between breeding and nonbreeding individuals, the method has been used to elucidate detailed predator-prey interactions at a variety of scales (e.g. Hunt et al. 1992, Veit et al. 1993). Furthermore, despite certain biases for some species 
(Spear et al. 1992, van Franeker 1994), the method is the only one available for many top predators.

Data from satellite transmitters have been used to analyse predator-prey interactions for a number of avian species, though these have mostly involved small numbers of large predators travelling relatively long distances (e.g Ancel et al. 1992, Davis \& Miller 1992, Weimerskirch et al. 1993, Jouventin et al. 1994j. Acquiring large enough samples of simultaneous data to characterise foraging ranges is expensive. For smaller species instruments are either still too large to deploy safely, or have known and/or potential effects on at-sea behaviour. For diving species of restricted foraging range these problems may be compounded by the difficulty of obtaining sufficient accurate positional fixes to reliably characterise foraging range. At present the macaroni penguin is at the margin of technical feasibility in these regards (cf. Davis \& Miller 1992, Kerry et al. 1997).

Methods that utilize time-based information from foraging trips in conjunction with details on activity budgets have been used for a number of predators (e.g. Croxall et al, 1984, Croxall \& Prince 1987); however, these methods are sensitive to the values which estimate foraging radius and though travel speed and activity are often relatively well known, the consistency and direction of travel are usually not. Thus, differences may exist between the theoretical foraging distribution and the areas actually used, particularly if it is assumed that foraging activity is uniform within a given theoretical range.

Aspects of at-sea predator distribution and predatorprey interactions, especially those relating to Antarctic krill Euphausia superba, have been studied around the subantarctic island of South Georgia for many years. The marine ecosystem at South Georgia supports very large predator populations, some of which are almost totally dependent upon krill. Since the 1970s, the region has also been the site of a large commercial fishery for krill, generating a potential overlap between predators and fishing vessels. Understanding the nature and magnitude of predator-prey interactions is therefore of direct concern where potential competition for resources relates to the size of krill taken by predators and nets (cf. Hill et al. 1996, Reid et al. 1996), or where direct overlap of foraging areas and fishing grounds exists. The predator-prey interactions around the island are thus of considerable interest both to conservation management and to commercial fleet operators.

In modelling the potential extent of predator foraging ranges at South Georgia, studies have mainly relied upon time-based information from foraging trips in conjunction with activity budgets (Pennycuick et al. 1984, Croxall et al. 1984, Croxall \& Prince 1987, Crox- all \& Briggs 1991), although recently, satellite tracking of certain larger species has become increasingly important (e.g. Prince et al. 1992, 1998, Rodhouse et al. 1996, Boyd et al. 1998). Data from direct observation as part of quantitative surveys for predator distribution are also available from a number of research cruises at South Georgia. However, these data have so far not been used to define predator foraging areas.

At South Georgia, one of the principal predators is the macaroni penguin Eudyptes chrysolophus Brandt, a species that feeds almost exclusively on krill $198 \%$ krill compared to $2 \%$ fish by mass) (Croxall \& Prince 1980, 1987, Croxall et al. 1988) and which has been estimated to take more than $50 \%$ of all krill consumed in the South Georgia region (Croxall et al. 1984). However, despite the importance of this relationship. there is no empirical description of where the main predator-prey interactions occur. Furthermore, it will be some time before sufficient satellite tracking data are available for this species, to provide such information.

In this study we use data collected during a shipbased quasi-synoptic quantitative survey of predatorprey distribution to define the foraging areas of macaroni penguins around South Georgia. The main objectives are: (1) to use at-sea observations of birds to examine the distribution of macaroni penguins; (2) to calculate a theoretical profile for the at-sea distribution in relation to the distance from their nearest breeding colony; (3) to compare the theoretical profile with that generated by previous models based on foraging trip duration and activity budgets; and (4) to use the profile to construct a foraging 'footprint' which can be used to represent those areas of particular importance to macaroni penguins, at least at the time of the study.

\section{METHODS}

Data collection at sea. Data were collected during cruise JB06 of the RRS 'John Biscoe'. The cruise was centred on the western end of South Georgia, where the largest macaroni penguin breeding concentrations in the region are situated and where $90 \%$ of the population breeds (Croxall et al. 1984). Radial transects were used that extended up to $130 \mathrm{~km}$ from a point just west of Bird Island ( $54^{\circ} 00.3^{\prime} \mathrm{S}, 38^{\circ} 10.2^{\prime} \mathrm{W}$ ) (Fig 1). The outer limit of the transects was set to be greater than the estimated mean maximum foraging range of macaroni. penguins (Croxall et al. 1984) and to go beyond the $1000 \mathrm{~m}$ depth contour The transects were steamed as part of 2 separate radial surveys carried out to record both predators and their prey in an integrated study (see Hunt et al. 1992, Veit et al. 1993). The first part, Survey 1, was carried out between 4 and 13 Feb- 
ruary 1986 and the second, Survey 2, between 16 and 23 February 1986. The mean peak fledging date for macaroni penguins at Bird. Island is 23 February (Williams \& Croxall 1991), thus both surveys were completed just prior to peak fledging.

During Survey 1, 2.5 transects were carried out each day, with one third starting at the inshore end close to Bird Island, one third starting at the outer end far from. Bird Island, and one third starting at an intermediate position midway along the transect (Hunt et al. 1992). Similarly during Survey 2 either 2 or 3 transects were carried out each day, alternating between pairs of transects to the north, or pairs of transects to the south of Bird Island. During each transect the number of seabirds and marine mammals was continuously counted whilst the ship steamed at a mean speed of $18.5 \mathrm{~km} \mathrm{~h}^{-1}$ (BIOMASS 1982). Only observations taken whilst the ship was actually steaming were included in the analyses. Observations were carried out during daylight hours between $\sim 07: 00$ and $\sim 22: 00 \mathrm{~h}$ GMT and were taken from a position approximately $10 \mathrm{~m}$ above the waterline; observations were restricted to those periods when visibility exceeded $300 \mathrm{~m}$. Sightings out to a distance of $300 \mathrm{~m}$ were recorded from within 1 forward quadrant defined by the longitudinal axis of the ship and the orthogonal axis through the bridge. Counts were carried out by teams of 3 people; 1 member of the team usually concentrated on flying seabirds, a second counted seals, penguins and seabirds sitting on the water, whilst the third entered the data directly into a microcomputer. Data were recorded as grouped counts, with each record indicating the species observed (henceforth referred to as observations) and the number of individuals of that species (referred to as counts).

Data analysis of bird observations. The position of observations, associated sea depth, and count for each recorded species were loaded into Arc/Tnfo 7.0.2 (ESRI), a Geographic Information System (GIS) used for ecological analysis (Trathan et al. 1993). The GIS contained map information for coastlines (McDonald et al. 1987) and bathymetry (Hydrographic Office 1992, Jones et al. 1994). As all data selections were carried out using the spatial database within Arc/Info, data were converted to a Lambert conformal projection in order to preserve shape and orientation and so that local scale in every direction around a given point was constant (scale error < 1\%) (Snyder 1987). Statistical analyses were carried out in Genstat 5 (Payne et al. 1993). Using the GIS, a series of 15 concentric circles centred at the survey centre were overlaid on the survey data. Each circle had a radius $10 \mathrm{~km}$ greater than the adjacent inner circle and was split into 4 equal sectors-northeast, northwest, southwest, and southeast. The area within each sector between adjacent circles was used as the basis for all analyses and each such area is henceforth referred to as a stratum. Within each stratum the length of survey track steamed was calculated, and using these values bird counts were normalised by track length (counts per $\mathrm{km}$ ). Thus, the counts of macaroni penguins during each survey were calculated along each transect for each stratum or sector.

One of the major analytical problems associated with data from at-sea predator surveys is the bias associated with large flocks of feeding birds. Though such records may indicate important ecological interactions, they can seriously affect any analysis due to the extreme skewness of the density distribution. During cruise JB06 a number of observations were recorded where the count of macaroni penguins was very high. For example, $40 \%$ of penguins counted were from observations where the number of penguins was greater than 20 , and 1 observation actually recorded 350 individuals, or almost $2 \%$ of the total number counted. As a consequence we used non-parametric tests (see Siegel 1956) to analyse the survey data, employing ranking methods where possible.

Population estimates for macaroni penguin colonies at South Georgia. The first estimate of breeding populations of macaroni penguins at all known South Georgia colonies was made by Croxall \& Prince (1979). Since then a few new colonies have been discovered and new estimates obtained for most other colonies (Prince \& Poncet 1996). In addition, the breeding population of a large colony (approximately 70000 pairs in 1976) at Bird Island has been counted annually since 1976. Many macaroni penguin colonies around northwest South Georgia (where the bulk of the breeding population is located) declined between the mid1970 s and the early 1980s. At the Bird Island study colony the population decreased by about $20 \%$ per annum from 1978 to $1981(n=88145-12891 \times t$; where $n$ is the number of pairs and $t$ is the time in years; $F_{1,2}=$ $227.3, p<0.050$, explains $98.7 \%$ of the variance; estimate 75254 pairs in 1978 and 36581 pairs in 1981) but has been fluctuating, though essentially stable, thereafter. For the present analysis all population counts were either estimates after 1986 or, for older counts, corrected to 1986 values based on the data from the Bird Island study colony (Table 1). Positions of all colonies are shown in Fig. 1.

Foraging footprint. A series of theoretical frequency distribution functions were fitted to the counts per $\mathrm{km}$ using Genstat 5 (Payne et al. 1993). In each analysis an iterative Gauss-Newton optimization method was used to estimate the approximate log-likelihood of the parameters for a series of curves. In each case, the residual deviance, fitted quartiles and fitted values were used to gauge the goodness of fit. A theoretical foraging 
Table 1 Eudyptes chrysolophus. Breeding colony counts for macaroni penguins at South Georgia in pairs $\times 10^{3}$ For Regions 1 to 14 the assessment of pairs is based on data in Croxall \& Prince (1979) that have been corrected to provide an estimate for 1986 (see text for details). For Regions 15 to 17 the assessment is taken from the breeding pair counts at newly discovered colonies reported by Prince \& Poncet (1996)

\begin{tabular}{|clrc|}
\hline Region & Area name & $\begin{array}{c}\text { Number of } \\
\text { colonies }\end{array}$ & $\begin{array}{c}\text { Assessment of } \\
\text { pairs in 1986 }\end{array}$ \\
\hline 1 & Willis Islands & 20 & 2560.0 \\
2 & Bird Island & 3 & 89.6 \\
3 & Elsehul & 1 & 2.6 \\
4 & Welcome Islets & 1 & 10.2 \\
5 & Hercules Bay & 3 & 30.7 \\
6 & Barff Peninsula & 3 & 5.1 \\
7 & Calf Head & 1 & 5.1 \\
8 & Royal Bay & 5 & 15.4 \\
9 & Cooper Bay & 2 & 7.7 \\
10 & Cooper Island & 5 & 15.4 \\
11 & Nattriss Head & 10 & 23.0 \\
12 & Pickersgill Islands & 1 & 5.1 \\
13 & Annenkov Island & 5 & 10.2 \\
14 & Cape Paryadin & 1 & 5.1 \\
15 & Cape North & 1 & 4.0 \\
16 & Sheathbill Bay & 1 & 1.0 \\
17 & Clerke Rocks & 9 & 14.6 \\
\hline
\end{tabular}

profile was determined using the fitted function that best described the at-sea counts. Using this profile, foraging footprints for each colony were generated using GIS spatial analysis techniques in Arc/Edit and Grid, component parts of Arc/Info. The colony population estimates were included in the GIS, and were apportioned over the potential foraging range according to the theoretical at-sea profile. As part of the spatial analysis for each colony footprint, foraging range was based upon the direct distance from the colony, taking into account the position of the colony and the shape of the island. Hence, the area was modified according to the size and shape of offshore islands, bays and headlands that occurred in each possible foraging direction. Modifications were carried out in Arc/Edit and in Grid at a resolution of $5 \mathrm{~km}$.

\section{RESULTS}

Survey 1 covered a wide region around the northwest of South Georgia with the principal objective of determining the atsea distribution and abundance of marine predators and their prey. Transects ex- tended 98 to $120 \mathrm{~km}$ (mean $113 \mathrm{~km}$ ) from the colony. Survey 2 was designed to cover a more restricted area, and intensively sampled areas of high density found during Survey 1. During Survey 2 transects extended 70 to $74 \mathrm{~km}$ (mean $72 \mathrm{~km}$ ) to the north and 103 to $118 \mathrm{~km}$ (mean $114 \mathrm{~km}$ ) to the south of Bird Island.

\section{Survey 1}

A number of issues were addressed using data from Survey 1, which were grouped under 3 headings: differences in bird numbers, differences in distribution in relation to direction and differences in distance from the colony.

\section{Difference in numbers}

To examine whether differences existed between transects, bird counts (average counts per km for each $10 \mathrm{~km}$ section of transect) were ranked across all transects and a Kruskal-Wallis 1-Way Analysis of Variance (adjusted for ties) was carried out. This indicated that there was no significant difference between the ranked counts for the different transects $\left(H_{19}=29.73\right.$, $\mathrm{p}>0.050$ ). A parametric 1-Way Analysis of Variance gave a similar result $\left(F_{19}=1.01, \mathrm{p}>0.100\right)$, indicating that bird counts for the transects were not significantly different.

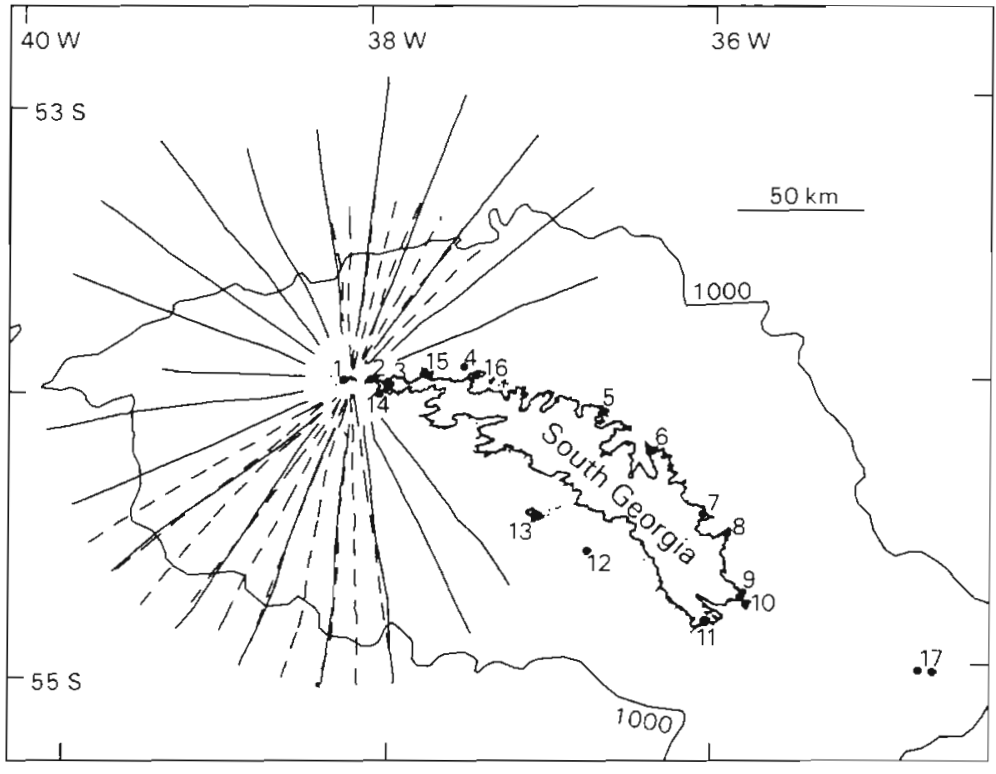

Fig. 1. Map of the study area showing South Georgia, the $1000 \mathrm{~m}$ isobath and the transects of the predator observation surveys, Survey 1 ( - ) and Survey $2(---)$. (•) Positions where major macaroni penguin breeding concentrations are located; labels as in Table 1 
Table 2. Eudyptes chrysolophus. Comparison of bird counts per $\mathrm{km}$ from Survey 1 after allocation to sectors. Results from a series of Kruskal-Wallis 1-way analysis of variance tests

\begin{tabular}{|lcccc|}
\hline Sector & Transects & $H$ & df & Probability \\
\hline Northeast (S1) & 5 & 4.99 & 4 & $\mathrm{p}>0.100$ \\
Northwest (S2) & 6 & 4.98 & 5 & $\mathrm{p}>0.100$ \\
Southwest (S3) & 6 & 3.86 & 5 & $\mathrm{p}>0.100$ \\
Southeast (S4) & 3 & 0.77 & 2 & $\mathrm{p}>0.100$ \\
Between sectors & 4 & 4.25 & 3 & $\mathrm{p}>0.100$ \\
\hline
\end{tabular}

\section{Direction from colony}

To explore whether macaroni penguins were found in preferred directions with greater numbers in certain regions, the 20 transects were allocated to 1 of 4 equalsized sectors - northeast, northwest, southwest or southeast. A series of Kruskal-Wallis 1-Way Analysis of Variance tests was then used to compare the bird count per $\mathrm{km}$ for each of the transects within a given sector. For all sectors, results (Table 2) indicated that the differences between transects within a sector were not significant.

To investigate the possibility that penguins were foraging in a preferred direction at a larger scale, bird counts were normalised by the total track length within each sector (counts per $\mathrm{km}$ ), and a further Kruskal-Wallis 1-Way Analysis of Variance test was used to compare the overall counts between the $4 \mathrm{sec}$ tors. The results from this test (Table 2) also indicated that there were no significant differences between sectors.

\section{Distance from colony}

To determine whether the distribution of macaroni penguins along each transect was uniform, counts per $\mathrm{km}$ were examined. For 10 of the 20 transects more than $75 \%$ of the total counts were within $40 \mathrm{~km}$ of the survey centre; for 16 of the transects, more than $75 \%$ were within the inner half $(65 \mathrm{~km})$. This general pattern with respect to distance from the colony was confirmed by using a Kruskal-Wallis 1-Way Analysis of Variance (adjusted for ties) to examine the ranked counts at different distances from the survey centre; this indicated that the ranked numbers were significantly different $\left(H_{13}=120.47, p<0.001\right)$ at different distances.

As macaroni penguins were not uniformly distributed along the transects, a series of Kendall coefficient of concordance tests (adjusted for ties) was used to compare the distribution of counts per $\mathrm{km}$ along the transects within each of the 4 sectors. The results
Table 3. Eudyptes chrysolophus. Comparison of bird counts per $\mathrm{km}$ from Survey 1 after allocation to sectors. Results from a series of Kendall coefficient of concordance tests

\begin{tabular}{|lccccc|}
\hline Sector & Transects & df & $W$ & $\chi^{2}$ & Probability \\
\hline Northeast (S1) & 5 & 13 & 0.64 & 41.3 & $\mathrm{p}<0.001$ \\
Northwest (S2) & 6 & 13 & 0.51 & 39.8 & $\mathrm{p}<0.001$ \\
Southwest (S3) & 6 & 13 & 0.45 & 34.8 & $\mathrm{p}<0.001$ \\
Southeast (S4) & 3 & 13 & 0.43 & 16.8 & $\mathrm{p}>0.100$ \\
\hline
\end{tabular}

(Table 3) indicated that the transects within 3 of the 4 sectors were not significantly different. Thus, similar relative distributions of penguins were recorded at similar distances along the transects within these 3 sectors. The results from the other sector, the southeast, showed that the distribution of birds was not the same for the different transects within that region.

To examine the distribution with respect to distance from the colony at a larger scale, the counts of macaroni penguins were compared for each of the 4 sectors. This was carried out by means of a series of Kolmogorov-Smirnov 2 sample tests that were based on the combined counts for each sector. These tests showed that there were some significant differences (Table 4); in particular the northeastern sector was dissimilar to all other sectors. A plot of the counts per $\mathrm{km}$ for the 4 sectors (Fig. 2) showed the general similarity between most sectors particularly in the large number of birds close to the survey centre; the plots also highlighted the northeastern sector which, unlike the others, had a large number of birds between 60 and $80 \mathrm{~km}$ and fewer close to the centre.

The results from Survey 1 indicated that there were no significant differences either in the number of macaroni penguins per transect, or in the direction that birds were foraging; however, there were differences in the distance that birds travelled from the colony.

Table 4. Eudyptes chrysolophus. Comparison of bird counts per $\mathrm{km}$ from Survey 1 after allocation to sectors. Below the diagonal are maximum differences from a series of Kolmogorov-Smirnov 2 sample tests, and above the diagonal are $\chi^{2}$ approximations to the statistic

\begin{tabular}{|c|c|c|c|c|}
\hline Sector & $\begin{array}{l}\text { Northeast } \\
\text { (S1) }\end{array}$ & $\begin{array}{c}\text { Northwest } \\
\text { (S2) }\end{array}$ & $\begin{array}{l}\text { Southwest } \\
\text { (S3) }\end{array}$ & $\begin{array}{l}\text { Southeast } \\
\text { (S4) }\end{array}$ \\
\hline Northeast (S1) & & $\begin{array}{c}14.1_{2,14} \\
(p<0.001)\end{array}$ & $\begin{array}{c}6.0_{2.14} \\
(p<0.050)\end{array}$ & $\begin{array}{c}9.8_{2,14} \\
(p<0.010)\end{array}$ \\
\hline Northwest (S2) & $\begin{array}{c}0.71_{14} \\
(p<0.005)\end{array}$ & & $\begin{array}{c}2.9_{2,14} \\
(p>0.100)\end{array}$ & $\begin{array}{c}7.3_{2,14} \\
(p<0.050)\end{array}$ \\
\hline Southwest (S3) & $\begin{array}{c}0.46_{14} \\
(p>0.050)\end{array}$ & $\begin{array}{c}0.32_{14} \\
(p>0.100)\end{array}$ & & $\begin{array}{c}1.0_{2,14} \\
(p>0.100)\end{array}$ \\
\hline Southeast (S4) & $\begin{array}{c}0.59_{14} \\
(p<0.050)\end{array}$ & $\begin{array}{c}0.51_{14} \\
(p>0.050)\end{array}$ & $\begin{array}{c}0.19_{14} \\
(p>0.100)\end{array}$ & \\
\hline
\end{tabular}



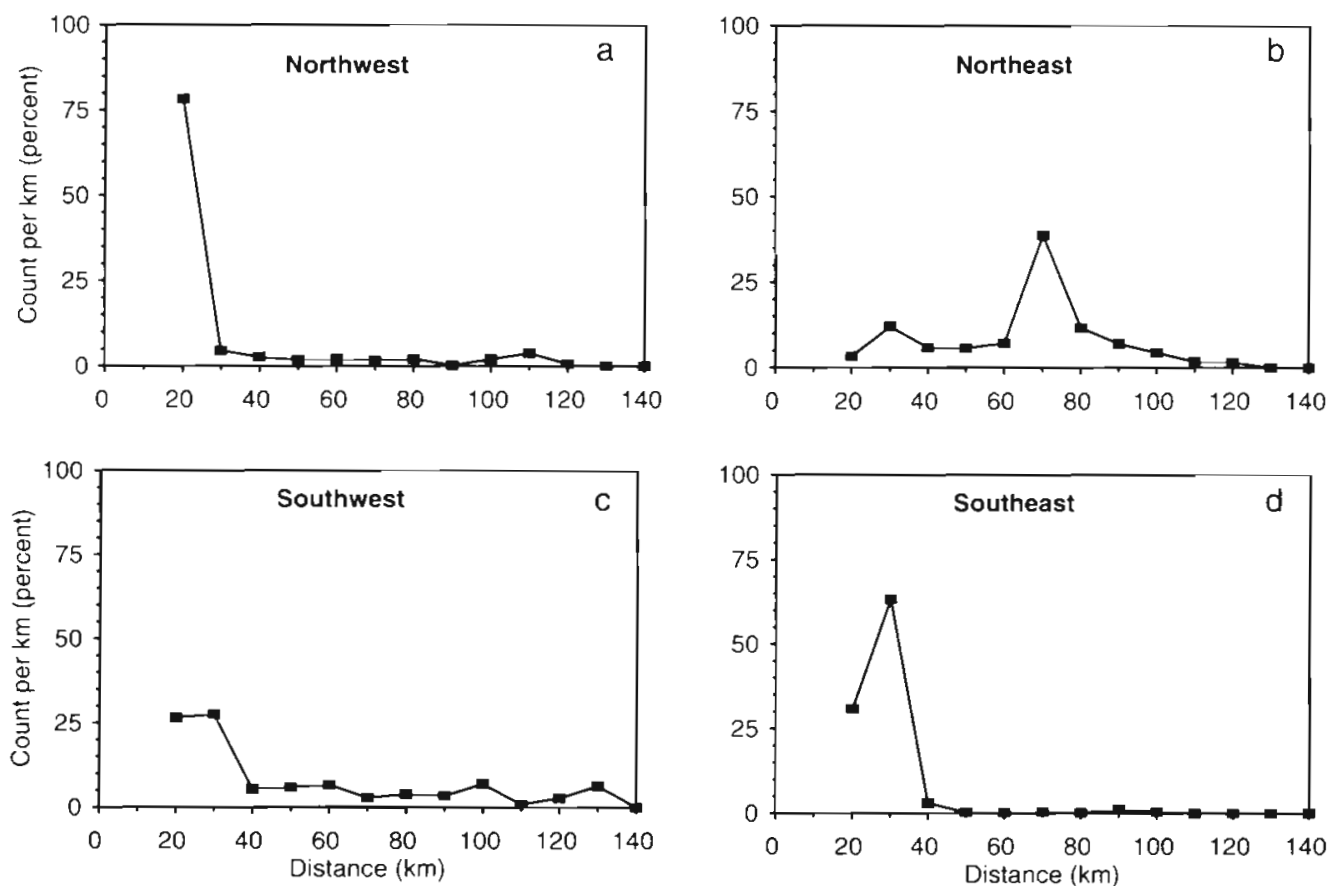

Fig. 2. Eudyptes chrysolophus. Distribution of counts per km during Survey 1 after allocation of counts to sectors; (a) northwest, (b) northeast, (c) southwest, and (d) southeast

\section{Survey 2}

The data from Survey 2 were collected at a slightly later date in the breeding season and so could be used to determine whether the same general results from Survey 1 were also evident at this later time. The data were examined using similar considerations to those for Survey 1; that is differences in bird numbers and differences in distribution in relation to distance. Survey 2 did not cover the whole foraging area (see Fig. 1), so no examination of direction was made. Following the results for Survey 1 (Tables $2 \& 3$ ), transects from Survey 2 were first allocated into 2 areas before analysis, with the first area to the north-northeast and the second to the south-southwest.

\section{Difference in numbers}

To examine whether differences existed between the 2 areas, bird counts (average counts per $\mathrm{km}$ for each $10 \mathrm{~km}$ stratum) were ranked across areas and a Wilcoxon matched-pairs test (adjusted for ties) carried out. The results of this test $\left(T_{12}=33.00, z=0.47, p>\right.$ 0.100 ) indicated that there were no significant differences between the ranked counts per area and that similar numbers were present in each area. A parametric $T$-test gave a similar result $\left(T_{12}=0.97, \mathrm{p}>\right.$ $0.100)$
Distance from colony

To determine whether the distribution of macaroni penguins was uniform over the survey area, counts per $\mathrm{km}$ were exannined. This indicated that the majority of macaroni penguins were close to the centre, with more than $80 \%$ of bird counts within $30 \mathrm{~km}$ of the survey centre. A Kolmogorov-Smirnov 2 sample test emphasised the similarity of the distributions $\left(D_{13}=0.42, \mathrm{p}>\right.$ $0.100 ; \chi_{2,13}^{2}=4.60, p>0.050$ ), with no significant difference between the 2 areas. A plot of the counts per $\mathrm{km}$ (Fig. 3) also showed the similarity between the 2 areas, with a large number of birds close to the survey centre and only relatively few further out.

\section{Comparison between Survey 1 and Survey 2}

To determine whether the distribution of macaroni penguins was similar during Survey 1 and Survey 2, the counts per $\mathrm{km}$ for each survey were compared. This was carried out for those areas where the surveys overlapped, that is at distances greater than $20 \mathrm{~km}$ from the survey centre. A KolnogorovSmirnov 2 sample test was used to compare the counts per $\mathrm{km}$ from both surveys. This comparison showed that there was no significant difference between the overall distribution in the surveys $\left(D_{12}=\right.$ $\left.0.21, p>0.100 ; \chi^{2} 2,12=1.05, p>0.100\right)$. A plot of the 

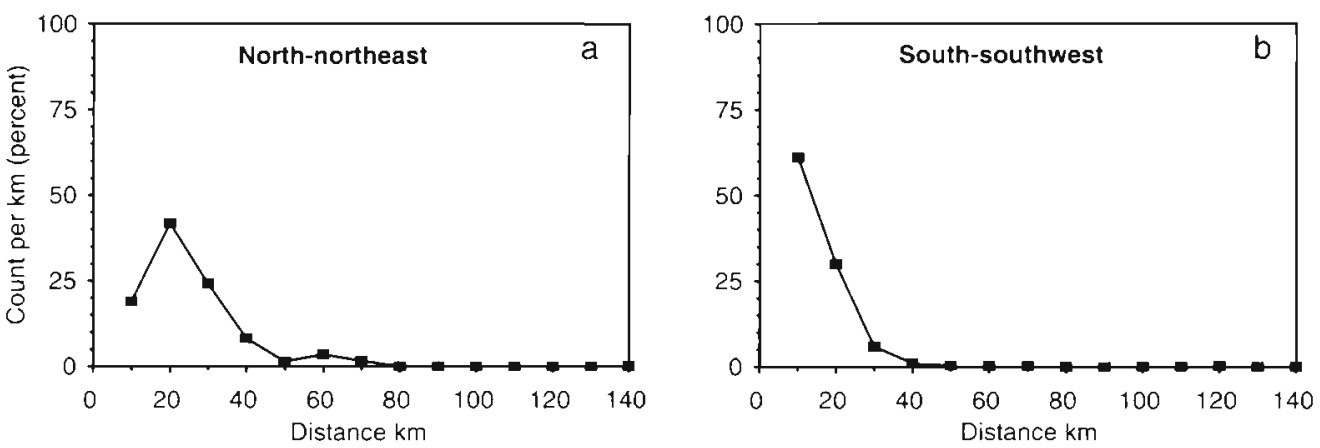

Fig. 3. Eudyptes chrysolophus. Distribution of counts per km during Survey 2 after allocation of counts to sectors; (a) north-northeast, (b) south-southwest

combined counts per km (Fig. 4) showed the similarity between the 2 surveys.

\section{Standard foraging profile for the at-sea distribution}

The at-sea counts from Survey 1 and Survey 2 suggest that the distribution of macaroni penguins was not uniform within the potential maximum foraging range. The observed distributions (Figs. 2 to 4 ) indicate that there were considerably more birds close to the centre of both surveys and that most birds were close to the colony, though some penguins were also recorded at greater distances, though not necessarily over permanent feeding grounds (compare Figs. 2b \& 3a). This result was evident at the scale of the individual transect (Table 3), and also at a much broader scale during both Survey 1 (Table 4) and Survey 2 (see above). The observed distributions were generally similar during the 2 surveys (Fig. 4), despite the potential biases associated with the low coverage close to the survey centre during Survey 1, and the low coverage to the west of the region during Survey 2.

A series of theoretical distribution functions fitted to the counts per $\mathrm{km}$ for each of the 4 sectors in Survey 1

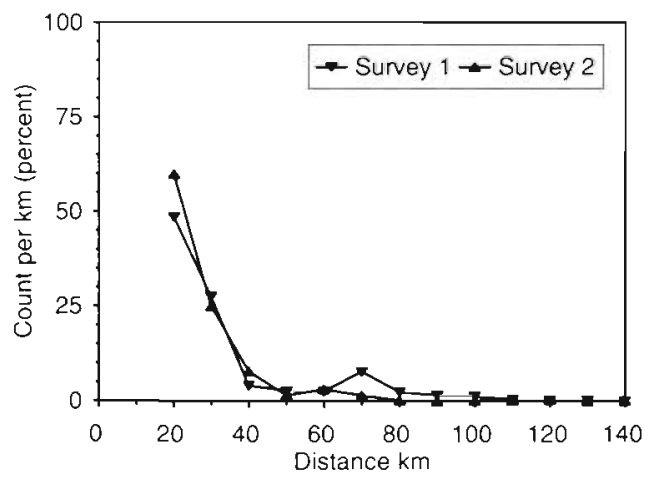

Fig. 4. Eudyptes chrysolophus. Distribution of counts per km during Survey 1 and Survey 2 after allocation of counts to a combined distribution for areas where the 2 surveys overlap and both of the 2 areas in Survey 2 adequately described the data; however, in all cases the residual deviance was high. In general, the long tail of the observed distributions and the area close to the centre of the survey (see Figs. $2 \& 3$ ) proved difficult to fit. Given the apparent importance of the area close to the centre of the survey, a further theoretical function was therefore fitted to the combined counts per $\mathrm{km}$ from Survey 2. A similar function was not fitted for Survey 1 due to the low coverage close to the survey centre. The function for Survey 2 was based upon the increase in area between adjacent strata and was of exponential form:

$$
f(x)=1 /\left(\pi r_{1}^{x}-\pi r_{2}{ }^{x}\right)
$$

where $r_{1}$ is the radius of a stratum, $r_{2}$ is the radius of the adjacent inner stratum, and $x$ is the order of the exponential. For the theoretical function fitted to the combined counts per km from Survey 2, $x$ was equal to 2.04 $\left(F_{2,12}=49.94, \mathrm{p}<0.050\right.$, explains $85.6 \%$ of the variance). A Kolmogorov-Smirnov goodness of fit test used to compare the observed values and the fitted values from the theoretical function indicated no significant difference $\left(D_{14}=0.25, \mathrm{p}>0.100\right)$. A plot of the counts per $\mathrm{km}$ for the fitted profile is shown in Fig. 5.

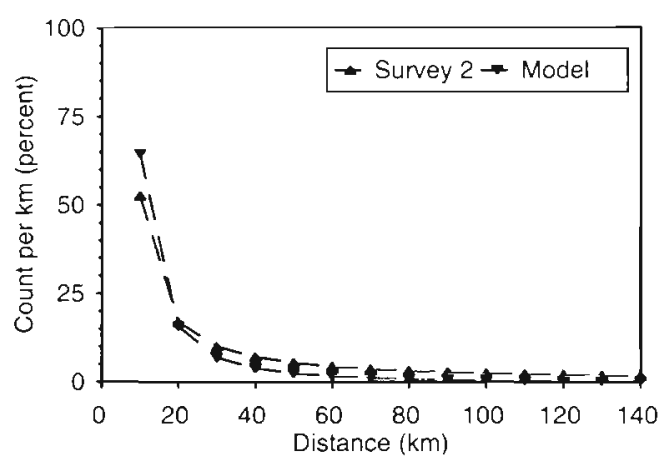

Fig. 5. Eudyptes chrysolophus. Fitted exponential distribution functions after allocation of counts to a combined distribution for Survey 2, and model standard profile distribution 


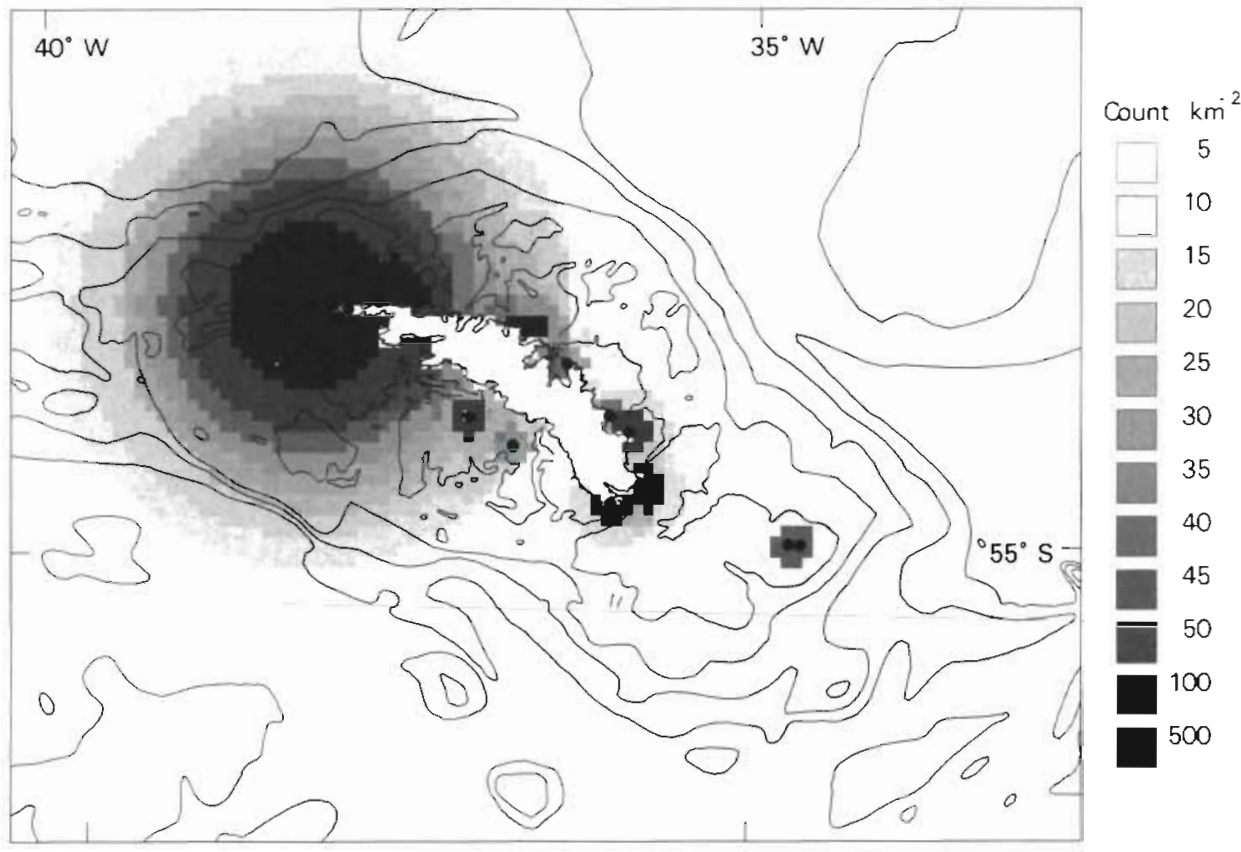

Fig. 6. Eudyptes chrysolophus. Theoretical foraging footprint for breeding colonies of macaroni penguins at South Georgia; (-) colony positions. The footprint is based on the at-sea theoretical distribution determined from Survey 2 (see text for details)

\section{Foraging footprint}

Survey 1 and Survey 2 each provide a synoptic view of the at-sea distribution of foraging macaroni penguins, and the standard profile (Fig. 5) is considered to provide a valid description of the overall foraging distribution during the latter part of the chick-rearing period in 1986. During both surveys, a large number of penguins were counted close to the centre of the area; however, Survey 2 had a greater spatial coverage in the centre. Thus, based on the high concentrations of birds within $40 \mathrm{~km}$ of the survey centre and the similarity of the 2 surveys beyond $20 \mathrm{~km}$ (Fig. 4), Survey 2 was considered to provide a better indication of the atsea distribution of macaroni penguins. Thus, we used the fitted exponential distribution determined for the combined areas of Survey 2 to construct a foraging footprint for the macaroni penguin breeding colonies on the Willis Islands.

The same profile was also used, with colony-specific modifications resulting from colony locations, to generate footprints for the other macaroni penguin breeding colonies at South Georgia (Fig. 1, Table 1). Each colony footprint was based on the estimate of breeding pairs for that colony. The composite footprint determined by summing the individual footprints is shown in Fig. 6 This is the first attempt to produce a regional foraging footprint for all the known colonies at South Georgia and for the total macaroni penguin population for the island.

\section{Bathymetric relationships}

At South Georgia the continental shelf mostly occurs at depths that are less than $250 \mathrm{~m}$ (Everson 1984, Hydrographic Office 1992); however, close to the island navigation is difficult and both surveys sampled only a small part where the depth was less than $100 \mathrm{~m}$. The shelf extends approximately $70 \mathrm{~km}$ from the island and Survey 1 gave the widest coverage extending in all directions from the survey centre. Thus, data from Survey 1 were used to examine relationships between sea depth and the at-sea position of macaroni penguins. Using the GIS, contours taken from Hydrographic Office (1992) were inspected to validate the depth data collected during the cruise. The depth over which the majority $(80 \%)$ of penguins were counted was less than $300 \mathrm{~m}$. Thus, for Survey $1,77 \%$ of penguins (1982 birds) were recorded over the shelf where water depth was less than $250 \mathrm{~m}, 17 \%$ (448 birds) were recorded over the shelf slope where the depth was between 250 and $500 \mathrm{~m}$, and $6 \%$ (158 birds) were recorded off the shelf where depth was greater than $500 \mathrm{~m}$ (Fig. 7). A similar analysis using data from Survey 2 produced comparable figures; thus, $84 \%$ of penguins $(4178$ birds) were recorded over the shelf, 13\% (643 birds) were recorded over the shelf slope, and 3\% (142 birds) were recorded off the shelf. Thus, the proportion of birds observed over deep water, compared to the proportion of transect surveyed over deep water $(\sim 41 \%$ of the total transect length was over water deeper than 


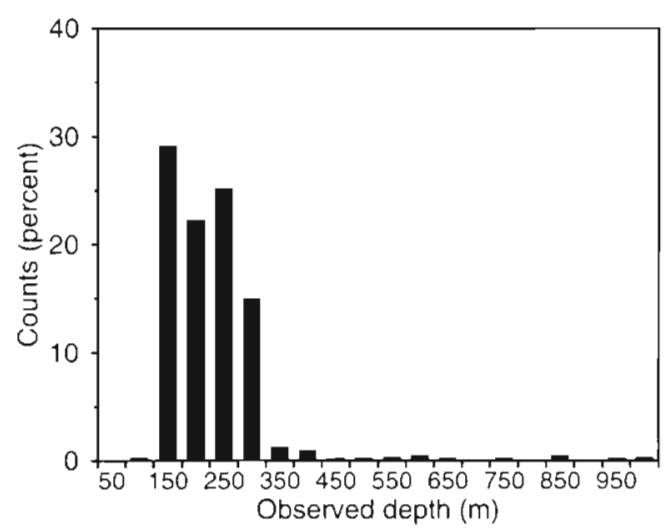

Fig. 7. Eudyptes chrysolophus. Histogram of recorded depths for all observations during Survey 1

$500 \mathrm{~m}$ during Survey 1 and $\sim 27 \%$ was over water deeper than $500 \mathrm{~m}$ during Survey 2), indicated that macaroni penguins mostly occurred over the shelf.

At present the distinction as to whether the foraging profile is related to distance or to depth is difficult to establish. Nevertheless, it is clear that most penguins were over the shelf and relatively few were over the shelf slope, or off the shelf.

\section{DISCUSSION}

The observations recorded during cruise JB06 provide a quasi-synoptic estimate of the at-sea distribution of macaroni penguins during the latter part of the breeding season. This distribution is based on a large number of bird observations, with more macaroni penguins counted than during any other research cruise around South Georgia. Thus, the foraging profile (Fig. 5) and the foraging footprint (Fig. 6) are based on the best dataset currently available to describe the spatial distribution of macaroni penguins at this time of year. Only with studies that combine at-sea observations with the use of satellite tags and activity recorders will a more complete picture of foraging distribution and behaviour emerge.

Here we discuss the foraging profile together with some of the more important potential causes of variability. We also discuss some of the ecological implications of the spatial pattern determined from the footprint and highlight its importance as a tool for examining potential overlap between commercial fisheries for krill and krill-dependent species.

\section{Standard foraging profile}

The fitted theoretical profile and footprint represent a density-distribution map of macaroni penguins. They indicate high numbers close to the colonies and relatively low numbers offshore (Fig. 5). The profile used to describe the at-sea counts is based on the increase in available foraging area. Thus, the exponent of the function indicates that the rate of decrease in penguin numbers is approximately equal to the rate of increase in area with increasing distance from the colony. This assessment of penguin numbers purely on the basis of area is probably an oversimplification of their foraging behaviour, yet the close fit of the model indicates the importance of this parameter in modelling their distribution.

The only previous attempt to model the at-sea distribution of macaroni penguins at South Georgia (Croxall et al. 1984) was explicitly designed to estimate the distribution of prey consumption and not the distribution of birds at sea. Thus, Croxall et al. (1984) assumed macaroni penguins were central-place-foragers (i.e. penguins travel from their breeding colony to a specific foraging zone where they collect food and then return to their colony), and that the profile of feeding distribution could be modelled by an exponential function with the majority of birds foraging near to their maximum potential foraging range. Thus, based on the duration of foraging trips and an average swimming speed of $1.9 \mathrm{~m} \mathrm{~s}^{-1}$, Croxall et al. (1984) determined that the bulk of prey consumption was located at 90 to $120 \mathrm{~km}$ from the colonies.

However, circumstantial evidence regarding foraging distance of macaroni penguins can be derived from studies using time-depth recorders (TDR). For example, Croxall et al. (1988) used TDRs to record foraging trips made from Bird Island, South Georgia during the breeding seasons of 1985 and 1986, and reported that most foraging trips made by females were either 12 or $24 \mathrm{~h}$ in duration, with the proportion of longer trips increasing through the season. After chicks joined crêches, foraging was undertaken by both males and females and trips were either 12,24 , or 48 h in duration (Croxall et al. 1988). Hence, the maximum possible range over which foraging penguins could travel would be $50 \mathrm{~km}$ for a $12 \mathrm{~h}$ trip, $100 \mathrm{~km}$ for a $24 \mathrm{~h}$ trip, or $200 \mathrm{~km}$ for a $48 \mathrm{~h}$ trip, assuming an average swimming speed similar to that reported by Clark \& Bemis (1979) from tank experiments $\left(2.3 \mathrm{~m} \mathrm{~s}^{-1}\right)$, or reported by Brown (1987) from at-sea measurements (mean $2.1 \mathrm{~m} \mathrm{~s}^{-1}$; range 1.9 to $2.3 \mathrm{~m} \mathrm{~s}^{-1}$ ). Penguins usually travel by swimming underwater, as opposed to at the surface. However only a proportion of dives are likely to be used as a means of commuting (cf. Trivelpiece et al. 1986). Thus, if macaroni penguins spend on average $48 \%$ (and up to $71 \%$ ) of their time diving (Croxall et al. 1993), any simple time-distance estimates may exaggerate the foraging range of macaroni penguins, possibly by as much as a factor of 2 
Assuming that the percentage of time spent foraging is proportional to the time spent in diving bouts, and that the percentage of time spent searching for prey patches is proportional to the inter-bout period (Boyd et al. 1996), the proportion of time spent feeding $(\tau)$ can be estimated. Thus, using data from Croxall et al (1993), a value of $\tau$ of 0.683 can be calculated, given that the mean time spent in diving bouts was $30.6 \mathrm{~min}$ and the mean time spent between bouts was $14.2 \mathrm{~min}$. Using this new value of $\tau$ in the foraging equation of Croxall et al. (1984) allows a new mean maximum foraging distance of $43 \mathrm{~km}$ to be calculated; with

$$
R=86.4 v(1-\tau) / 2 z \phi
$$

where $R$ is the range in $\mathrm{km}, 86.4$ is a conversion factor to convert from $\mathrm{m} \mathrm{s}^{-1}$ to $\mathrm{km} \mathrm{d}^{-1}, v$ is the travel speed in $\mathrm{m} \mathrm{s}^{-1}, \tau$ is the proportion of time spent feeding, 2 is a correction factor to allow for inward and outward travel, $z$ is a correction factor for indirect travel, and $\phi$ is the feeding frequency. Apart from $\tau$, parameter values were the same as those used by Croxall et al. (1984); thus $v=1.9 \mathrm{~m} \mathrm{~s}^{-1}$, travel was assumed to be direct for penguins therefore $z=1$, and $\phi=0.6$ meal chick ${ }^{-1}$ adult ${ }^{-1} \mathrm{~d}^{-1}$.

The revised feeding distribution profile based on the model of Croxall et al. (1984) would therefore distribute feeding activity within $45 \mathrm{~km}$ of the colony, which is consistent with the range revealed by our analysis of at-sea observations. Thus, the approach of Croxall et al. (1984), when newly available activity time budget data are incorporated, also highlights the importance of the shelf region at South Georgia.

Although the foraging areas circumscribed by the 2 models may be similar, the distribution of feeding within these areas could be quite different. If macaroni penguins are central-place-foragers, the high density of penguins close inshore will mostly reflect commuting birds, whereas the relatively lower densities further offshore will potentially reflect actual feeding effort. At present there are few available data that describe the at-sea foraging activities of macaroni penguins, although periods of feeding and searching (travelling) appear to be approximately evenly distributed throughout the foraging trip (Croxall et al. 1993). Therefore the actual distribution of prey consumption is probably less concentrated inshore than indicated by at-sea observations, and probably less concentrated offshore than indicated by centralplace-foraging theory.

\section{Potential causes of variability in the foraging footprint}

Whatever the relationship between the foraging footprint and the distribution of prey consumption, the relationship is likely to change substantially within and between years. The main sources of variability will be the degree of constraint on the foraging ranges of penguins and the nature of mesoscale distribution and abundance of their prey.

The penguins observed in this study were recorded during the breeding season, however no distinction can be made between breeding and non-breeding birds. Non-breeding birds (including juveniles under $8 \mathrm{yr}$ old) represent a large proportion (ca 50\%) of the population and therefore generate a significant prey demand, yet without a chick to feed non-breeding birds are likely to be less restricted in their foraging range. Thus, the proportion of birds foraging in any particular stratum may be influenced by the number of juveniles and non-breeding birds in the population.

Besides possible differences between breeding and non-breeding birds, there are also likely to be differences within the breeding season. For example, foraging trips differ in length with trips of approximately 20 to $30 \mathrm{~d}$ during courtship and incubation, 0.5 to $1.5 \mathrm{~d}$ during the brooding period, and 1 to $3 \mathrm{~d}$ during chick rearing. After fledging there is a 10 to $15 \mathrm{~d}$ trip prior to the moult period ashore (Croxall 1984, Williams \& Croxall 1991). Hence, it is likely that numbers in any particular stratum would change through the breeding season as penguins were able to make different length foraging trips. Thus, within a given distance of the colony, demand would vary throughout the season. The period of the at-sea observations made during cruise JB06 represents a time of year when penguins are particularly constrained to forage in relatively inshore areas. Outside the breeding season no comparable dataset exists for determining the foraging footprint of macaroni penguins at South Georgia; however, the location of foraging areas and the associated food availability will be important, and may determine future breeding fitness (cf. Trathan et al. 1996).

The at-sea data suggest that macaroni penguins were spreading radially from the breeding colonies and were targeting locally abundant sources of prey, most of which were in close proximity to the Willis Islands (Figs. 2 to 4); penguins did not appear to be travelling to and from a few permanent feeding grounds (compare Figs. $2 b \& 3 a$ ). Variation, both within and between years, in the distribution and abundance of prey in the South Georgia region is likely to influence the local distribution of predators. Thus, the high levels of krill recorded in some years (e.g. Murphy et al. 1991, Trathan et al. 1995) are not present every year and variation in abundance (cf. Priddle et al. 1988, Siegel 1988, Brierley et al. 1997) is likely to be an important feature of the ecosystem. Thus, prey concentrations may be reflected by an altered foraging footprint. In the year that JB06 was carried out, high densities of krill were recorded in the 
vicinity of Bird Island, close to the area where large numbers of macaroni penguins were observed (Hunt et al. 1992, Veit et al. 1993).

Despite the potentially high level of variation in the foraging footprint, the approach used in this study provides a new method for generating an estimate of the foraging distribution of penguins at times of year when they are particularly constrained. The methodology can be readily modified for other times of year and to other breeding sites, and is of practical applicability until such times as empirical estimates of at-sea distribution can be obtained by other methodologies.

\section{Ecological implications of the footprint}

The series of overlapping foraging zones in the foraging footprint indicates where penguin densities are greatest (Fig. 6), that is at the western end of South Georgia where the majority of macaroni penguins breed (Fig. 1, Table 1). Less-dense foraging zones occur around the few smaller colonies along the northern coast and on the southern offshore islands. The distribution of colonies is very similar to that for Antarctic fur seals Arctocephalus gazella (Boyd 1993), the main mammalian consumer of krill at South Georgia. The distribution is also consistent with the pattern of baleen whale catches recorded during the period 1923 to 1931 (Everson 1984). Thus, despite their different foraging constraints, the combined prey demand from these krill consumers is largely at the western end of the island. Therefore, it is likely that this reflects a longstanding high, and more regular, availability of prey in that area.

The oceanography of the area to the northwest of South Georgia is very variable (Trathan et al. 1997). In particular, the Southern Antarctic Circumpolar Current Front (SACCF), which marks the northern boundary of the subpolar waters of the Weddell-Scotia Confluence (WSC), flows close to the northern edge of the South Georgia shelf (Orsi et al. 1995). North of the Willis Islands the westward flowing SACCF meets the eastward flowing waters of the main Antarctic Circumpolar Current (ACC), and predators breeding at colonies to the northwest of South Georgia are within foraging range of both watermasses. As krill are not thought to breed around South Georgia, but to arrive in the WSC and the ACC (Everson 1977), hydrographic variability in these 2 watermasses may be important (Priddle et al. 1988). Thus, it is feasible that predators which are able to utilize prey from both sources may be able to breed more successfully and sustain larger breeding populations (cf. Clode 1993).

As krill are transported to South Georgia in the waters of the WSC and the ACC, physical variability outside the foraging range of predators could have profound consequences for predators breeding on the island. In a similar manner, upstream biological influences could be important, for example, consumption levels at other predator colonies, or commercial fishing may influence prey availability.

\section{Interactions with the local commercial krill fishery}

The commercial krill fishery at South Georgia operates almost exclusively along the northern shelf edge (Murphy et al. 1997. Trathan et al. in press) in the fast moving waters along the shelf edge (Brandon et al. in press). The restricted nature of the fishery implies that fishable concentrations of krill are not readily accessible over the shelf. However, the large number of penguins recorded offshore ( 60 to $90 \mathrm{~km}$ ) to the northeast of Bird Island during Survey 1 (Fig. 2b) coincides with the location of the fishery in some years. Thus, understanding macaroni penguin foraging behaviour patterns is particularly important during years when there is possible competition with the local krill fishery (cf. Murphy et al. 1997, Trathan et al. in press). In most years, direct competition might be thought to be minimal as most (>94\%) of the commercial fishing effort (and catch) at South Georgia occurs in winter (Everson \& Goss 1991), outside the penguin breeding season (November to March) (cf. CCAMLR 1996). In some years however, both commercial effort and krill catch are substantial during the breeding season. For example in 1987 almost $11 \%$ of the effort and more than $15 \%$ of the catch was taken during the months January to March (CCAMLR 1996), whilst in 1984 more than $90 \%$ of the catch was taken between January and February (CCAMLR 1996). Further, it may be that prey availability in winter prior to breeding and after moult is equally critical to the reproductive performance and survival of macaroni penguins (cf. Trathan et al. 1996). At present there is virtually no information regarding the winter diet and distribution of macaroni penguins, let alone possible overlap with the commercial krill fishery at that time of year.

Acknowledgements. We thank the officers and crew of the RRS 'John Biscoe' for support during the field program, George Hunt, Dennis Heinemann, Dick Veit, Nancy Harrison, Mick Whitehouse, Geoff Cripps, Billy Graham, Bob Morgan, John Warren and numerous British Antarctic Survey scientists collected the at-sea data. The development of the marine GIS was partially sponsored by a grant from The World Wide Fund for Nature (UK). Finally, we thank the editor and 3 anonymous referees for their valuable comments on an earlier draft of the manuscript. 


\section{LITERATURE CITED}

Ancel A, Kooyman GL, Ponganis PJ, Gendner JR, Lignon J, Mestre X, Huin N, Thorson PH, Robisson P, Le Maho $Y$ (1992) Foraging behaviour of emperor penguins as a resource detector in winter and summer. Nature 360 $336-339$

BIOMASS (Biological Investigation of Marine Antarctic Systems and Stocks) (1982) Recording observations of birds at sea. BIOMASS Working Party on Bird Ecology. BIOMASS Handbook Number 18, SCAR, Cambridge

Boyd IL (1993) Pup production and distribution of breeding Antarctic fur seals (Arctocephalus gazella) at South Georgia. Antarct Sci 5:17-24

Boyd IL, McCafferty DJ, Reid K, Taylor R, Walker TR (1998) Dispersal of male and female Antarctic fur seals (Arctocephalus gazella). Can J Fish Aquat Sci 55 (in press)

Boyd IL, Reid K, Bevan RM (1996) Swimming speed and allocation of time during the dive cycle in Antarctic fur seals. Anim Behav 50:769-784

Brandon MA, Murphy EJ, Whitehouse MJ, Trathan PN, Murray AWA, Bone DG, Priddle $J$ (in press) The shelf break front to the east of the sub-Antarctic island of South Georgia. Cont Shelf Res

Brierley AS, Watkins JL, Murray AWA (1997) Interannual variability in krill abundance at South Georgia. Mar Ecol Prog Ser 150:87-98

Brown CR (1987) Travelling speed and foraging range of macaroni and rockhopper penguins at Marion Island. J Field Ornithol 58:118-125

Buckland ST, Anderson DR, Burnham KP, Laake JL (1993) Distance sampling. Estimating abundance of biological populations. Chapman and Hall, London

CCAMLR (Commission for the Conservation of Antarctic and Marine Living Resources) (1996). Statistical bulletin. CCAMLR, Hobart

Clark BD, Bemis W (1979) Kinematics of swimming of penguins at the Detroit Zoo. J Zool 188:411-428

Clode D (1993) Colonially breeding seabirds - predator or prey. Trends Ecol Evol 8:336-338

Croxall JP (1984) Seabirds. In: Laws RM (ed). Antarctic ecology, Vol 2. Academic Press, London, p 533-619

Croxall JP, Briggs DR (1991) Foraging economics and performance of polar and subpolar A.tlantic seabirds. Polar Res 10:561-578

Croxall JP, Briggs DR, Kato A, Naito Y, Watanuki Y, Williams TD (1993) Diving patterns and performance in the macaroni penguin Eudyptes chrysolophus. J Zool 230:31-47

Croxall JP, Davis RW, O'Connell MJ (1988) Diving patterns in relation to diet of gentoo and macaroni penguins at South Georgia. Condor 90:157-167

Croxall JP, Prince PA (1979) Antarctic seabird and seal monitoring studies. Polar Record 19:573-595

Croxall JP, Prince PA (1980) The food of gentoo penguins Pygoscelis papua and macaroni penguins Eudyptes chrysolophus at South Georgia. Ibis 122:245-253

Croxall JP, Prince PA (1987) Seabirds as predators on marine resources, especially krill, at South Georgia. In: Croxall JP (ed) Seabirds: feeding ecology and role in marine ecosystems. Cambridge University Press, Cambridge, p 347-368

Croxall JP, Ricketts C, Prince PA (1984). Impact of seabirds on marine resources, especially krill, of South Georgia waters. In: Whittow GC, Rahn H (eds) Seabird energetics. Plenum Publishing Corporation, New York, p 285-317

Davis LS, Miller GD (1992) Satellite tracking of Adelie penquins. Polar Biol 12:503-506

Everson I (1977) The living resources of the southern ocean.
Southern Ocean Fisheries Survey Programme GLO/SO/ 77/1. FAO, Rome

Everson I (1984) Marine interactions. In: Laws RM (ed) Antarctic ecology. Academic Press, London, p 783-819

Everson I, Goss C (1991) Krill fishing activity in the southwest Atlantic. Antarct Sci. 3:351-358

Hill HJ, Trathan PN, Croxall JP, Watkins JL (1996) A comparison of Antarctic krill (Euphausia superba Dana) caught by nets and taken by macaroni penguins (Eudyptes chrysolophus Brandt): evidence for selection? Mar Ecol Prog Ser 140:1-11

Hunt GL, Heinemann D, Everson I (1992) Distribution and predator-prey interactions of macaroni penguins, Antarctic fur seals, and Antarctic krill near Bird Island, South Georgia. Mar Ecol Prog Ser 86:15-30

Hydrographic Office (1992) The approaches to South Georgia, Admiralty Chart 3596. Hydrographic Office, Taunton

Jones MT, Tabor AR, Weatherall P (1994) Supporting volume to the GEBCO digital atlas. British Oceanographic Data Centre, Bidston

Jouventin P, Capdeville D, Cuenotchaillet F, Boiteau C (1994) Exploitation of pelagic resources by a non-flying seabird-satellite tracking of the king penguin throughout the breeding cycle. Mar Ecol Prog Ser 106:11-19

Kerry KR, Clarke JR, Eberhard S, Gardner H, Lawless RM, Trémont R, Wienecke BC, Corsoloni S, Focardi S, Franchi $E$, Rodary $D$, Thomson $R$ (1997) The foraging range of Adélie penguins - implications for CEMP and interactions with the krill fishery. CCAMLR Sci 4:75-87

McDonald DIM, Storey BC. Thomson JW (1987) Geological map of South Georgia. BAS GEOMAP Series, Sheet 1, 1. 250 000. British Antarctic Survey, Cambridge

Murphy EJ (1995) Spatial structure of the Southern Ocean ecosystem: predator-prey linkages in the Southern Ocean food webs. J Anim Ecol 64:333-347

Murphy EJ, Everson I, Murray AWA (1991) Analyses of acoustic line-transect data from the waters around South Georgia: estimation of krill (Euphausia superba Dana) biomass. Scientific Committee for the Conservation of Antarctic Marine Living Resources Selected Scientific Papers, Hobart, Australia. SC-CAMLR-SSP/8:225-243

Murphy EJ, Trathan PN, Everson I, Parkes G (1997) Krill fishing distribution around South Georgia. CCAMLR Sci 4: $1-18$

Orsi AH, Whitworth TIII, Nowlin WD Jr (1995) On the meridional extent of the Antarctic Circumpolar Current. Deep Sea Res 42:641-673

Payne RW, Lane PW, Digby PGN, Harding SA, Leech PK, Morgan GW, Todd AD, Thompson R, Tunnicliffe Wilson G, Welham SJ, White RP (1.993) Genstat 5 release 3 reference manual. Clarendon Press, Oxford

Pennycuick CJ, Croxall JP, Prince PA (1984) Scaling of foraging radius and growth-rate in petrels and albatrosses (Procellariiformes). Ornis Scand 15:145-154

Priddle J, Croxall JP, Everson I, Heywood RB, Murphy EJ, Prince PA, Sear CB (1988) Large-scale fluctuations in distribution and abundance of krill-a discussion of possible causes. In: Sahrhage D (ed) Antarctic Ocean and resources variability. Springer, Berlin, p 169-182

Prince PA, Croxall JP, Trathan PN, Wood AG (1998) The pelagic distribution of South Georgia albatrosses and their relationships with fisheries. In: Robertson G, Gales R (eds) Albatross biology and conservation. Surrey Beatty and Sons, Chipping Norton, Australia, p 137-167

Prince PA, Poncet S (1996) South Georgia distribution of Macaroni penguins (Eudyptes chrysolophus), Map 2-11. In: Trathan PN, Daunt FHJ, Murphy EJ (eds) South Georgia: 
an ecological atlas. British Antarctic Survey, Cambridge

Prince PA, Wood AG, Barton T, Croxall JP (1992) Satellite tracking of wandering albatrosses (Diomedea exulans) in the South Atlantic. Antarct Sci 4:31-36

Reid K, Trathan PN, Croxall JP. Hill HJ (1996) Krill caught by predators and nets: differences between species and techniques. Mar Ecol Prog Ser 140:13-20

Rodhouse PG, Prince PA, Trathan PN, Hatfield EMC, Watkins JL, Bone DG, Murphy EJ, White MG (1996) Cephalopod community associated with mesoscale oceanographic features at the Antarctic Polar Front exploited by satellite tagged predators. Mar Ecol Prog Ser 136:37-50

Siegel S (1956) Nonparametric statistics for the behavioral sciences. McGraw-Hill Kogakusha Ltd, Tokyo

Siegel V (1988) A concept of seasonal variation of krill (Euphausia superba) distribution and abundance west of the Antarctic Peninsula. In: Sahrhage D (ed) Antarctic ocean and resources variability. Springer, Berlin, p 219-230

Snyder JP (1987) Map projections-a working manual. US Geological Survey professional paper 1395. US Government Printing Office, Washington, DC

Spear LB, Ainley DG, Nur N (1992) Estimating absolute densities of flying seabirds using analyses of relative movement. Auk 109:385-389

Trathan PN, Brandon MA, Murphy EJ (1997) Characterisation of the Antarctic Polar Frontal Zone to the north of South Georgia in summer 1994. J Geophys Res 102:10483-10497

Editorial responsibility: Otto Kinne (Editor),

Oldendorf/Luhe, Germany
Trathan PN, Croxall JP, Murphy EJ (1996) Dynamics of Antarctic penguin populations in relation to inter-annual variability in sea-ice distribution. Polar Biol 16:321-330

Trathan PN, Everson l, Miller DGM, Watkins JL, Murphy EJ (1995) Krill biomass in the Atlantic. Nature 373:201-202

Trathan PN, Everson I, Murphy EJ, Parkes G (in press) Analysis of trawl data from the South Georgia krill fishery. CCAMLR Sci

Trathan PN, Murphy EJ, Symon CJ, Rodhouse PG (1993) Ecological and oceanographic relationships in the Southern Ocean. GIS Europe 2:34-36

Trivelpiece WZ, Bengtson JL, Trivelpiece SG, Volkman NJ (1986) Foraging behaviour of gentoo and chinstrap penguins as determined by new radiotelemetry techniques. Auk 103:777-781

van Franeker JA (1994) A comparison of methods for counting seabirds at sea in the Southern Ocean. J Field Ornithol 65 96-108

Veit RR, Silverman ED, Everson I (1993) Aggregation patterns of pelagic predators and their principal prey, Antarctic krill, near South Georgia. J Anim Ecol 62:551-564

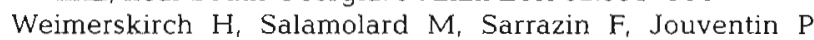
(1993) Foraging strategy of wandering albatrosses through the breeding season: a study using satellite telemetry. Auk 110:325-42

Williams TD, Croxall J P (1991) Annual variation in breeding biology of macaroni penguins, Eudyptes chrysolophus, at Bird Island, South Georgia. J Zool 223:189-202

Submitted: January 23, 1998; Accepted: May 18, 1998 Proofs received from author(s): July 24, 1998 